\title{
PERCEPTIONS OF AUTOMATED DATA COLLECTION TECHNOLOGY USE IN THE CONSTRUCTION INDUSTRY
}

\author{
Javad MAJROUHI SARDROUD \\ Faculty of Engineering, Islamic Azad University, Central Tehran Branch, Tehran, \\ Iran Niyaresh University Complex, BLV Emam Hasan, Ponak Square, Tehran, Iran
}

Received 15 Jun 2012; accepted 07 Aug 2012

\begin{abstract}
Research projects have indicated development of several technical solutions for the management of construction activities. However, little attention has been paid to the issues regarding the adoption and implementation of these techniques. This study investigates the perception of Automated Data Collection (ADC) technology usage in construction, and identifies reasons why available ADC technology has not been fully introduced in construction. A comprehensive literature review carried out in this research identifies barriers to the adoption of ADC technology. In total, 19 key factors are identified as barriers for adoption of ADC technology in construction, and validated through an international questionnaire survey. According to the results, process related factors play an essential role in adopting automated data acquisition technologies in the construction industry. In order to form the backbone of technology adoption in real scenarios, and to identify driving factors in this field, this paper also introduces an implementation framework for ADC technology in the construction industry.
\end{abstract}

Keywords: adoption strategy, automated data collection technologies, construction industry, implementation framework.

\section{Introduction}

The construction industry is both highly complex and fragmented compared to other industries, because its products are unique in its construction type, project participants, and location. This high degree of fragmentation has been highlighted by many researchers as a fundamental barrier to be overcome in order to achieve the successful implementation of new technologies (Nigithamyong, Skibniewski 2004). Furthermore, construction is recognised internationally as one of the labour and information-intensive industries which are subject to an open environment and harsh conditions (Bowden et al. 2006; Behzadan et al. 2008). Thus, accurate and real time information systems have become an important tool in the management of construction projects (Majrouhi Sardroud 2012).

Recently, Information and Communication Technology (ICT) has received a great deal of attention and some solutions have been developed to assist the management activities throughout various industries. One of the current significant issues involved with ICT is Automated Data Collection (ADC) technology that also known as Automated Data Capture; the use of which has grown in recent years. Some researchers highlighted importance of using these technologies in construction (Navon, Goldschmidt 2002; Navon 2007; Caldas et al. 2004). ADC technologies can be defined as the use of automated advanced and data storage technologies for the identification, collection, storage, transmission, and presentation of information (Caldas et al. 2004; Majrouhi Sardroud, Limbachiya 2010). Barcode, Global Positioning System (GPS), and Radio Frequency Identification (RFID) are examples of such kind of technologies. Automated data collection devices are continuously evolving and becoming common in industries such as logistics and manufacturing, and can be of great convenience on construction job sites, supporting automatic access to reliable realtime information of on-site materials (Caldas et al. 2004).

In addition, advanced ADC technologies that can be used for real-time on-site measurement of performance indicators are rapidly emerging, and their costs are declining (Navon, Sacks 2007). Thus, ADC technologies are capable to facilitate paperless management of construction activities, modernise information collection and sharing, and undoubtedly have a profound impact on effective management of construction activities.

Automated data collection technologies have the potential to improve information integration and enhancing team collaboration and communication (Zavadskas 2010). Although ADC technologies offer new opportunities to establish effective management tools, research studies have indicated the construction industry is a late 
adopter of ADC technologies (Love et al. 2004). In view of this, the study investigates the perception of ADC technology usage in the construction industry and identifies reasons why available ADC technologies were not fully introduced in the construction industry. This paper summaries results obtained from construction-related participants from across the globe based on a questionnaire survey.

\section{Literature review}

According to Razavi and Haas (2010), the main aim of using automated data collection (ADC) technologies in construction is to increase efficiency, reduce data entry errors caused by human transcription, reduce labour costs, and reduce bottlenecks. The increasing need for measuring and controlling construction operations and monitoring information and the rapid technological developments in ADC technologies and their declining costs are the two major aspects driving research in this direction (Zavadskas 2010). ADC technologies applicable to construction sites vary in functionality, accuracy, cost and application scope.

The advancement and wide application of ADC technologies make construction sites more intelligent and integrated where materials, components, tools, equipment, and people will become elements of a fully sensed and monitored environment (Liang et al. 2011). For example, technological developments in the ADC technologies enhance real time construction data to be collected (Navon 2005) and enable automated measurement of the performance of earthmoving operations (Navon et al. 2004). Automated tracking the location of tagged objects (e.g. materials, equipment and labour) on site precisely has become technically more viable with recent advances in ADC technologies (Song et al. 2006). In summary, the existing approaches to accurately tracking location of materials imply economically prohibitive deployment of ADC technologies (Song et al. 2007).

However, the realisation of potential benefits of IT use in practice has been limited, and the magnitude of automated data collection technologies usage in the construction industry remains low as compared to other industries (Love et al. 2004), even if it is claimed to be beneficial. One significant reason is due to lack of understanding of how to implement information and communication technology into a construction organisation (Peansupap, Walker 2005). Another possible reason is due to low return on investment (ROI), perhaps due to construction focusing too much on cost reduction and short-term ROI (Barthorpe et al. 2003).

\subsection{Technology adoption barriers}

In order to identify barriers to the effective implementation of information and communication technologies in construction, several surveys have been conducted in various countries (Barthorpe et al. 2003; Ahuja et al.
2009; Adriaanse et al. 2010a). Earlier research studies indicate cost and technological problems that create barriers to ICT adoption and its use within the construction industry. However, a recent study has shown that the barriers of information and communication technology use and adoption have moved beyond technical and cost problems to ICT management problems within the construction organisations (O'Brien 2000).

In a research conducted by Adriaanse et al. (2010a), it is concluded that fundamental characteristics of construction projects, such as the fragmented and temporary nature of construction projects, different working practices, resources, and the objectives of the organisations involved causes most of the barriers to the intended use of inter organisational ICT.

A fundamental barrier to IT adoption is the inherent difficulty associated with identifying and assessing benefits and costs associated with IT adoption. In particular, construction organisations remain uncertain about the expected impact the investment might have on the business. In addition, the issue of "Culture" has gained attention as one of the important factors, influencing both the success of, and barriers to ICT engagement (Gajendran, Brewer 2007). As a result, it is all too easy for businesses and management to ignore, or ineffectively evaluate their IT investment (Love et al. 2004). In another study, Love et al. (2001) revealed several problematic ICT implementation issues such as lack of an IT infrastructure, staff, business requirements and investment cost, unclear benefits of ICT use, and behavioural barriers.

According to a research which has been conducted to examine the current use of state of ICT by United Kingdom construction companies, the three most significant non-financial barriers to the effective implementation of ICT in the UK construction industry were: a lack of established IT system standards, traditional business practice of the construction industry and the fragmented nature of this industry (Barthorpe et al. 2003).

Frits (2007) stated that one of the reasons why available ICT technology was not fully introduced in construction companies is due to lack of perceived suitability of the software. In addition, the study explained the slow ICT uptake as being a consequence of; the complex nature of the construction industry, ICT immaturity levels, poor availability of tools for evaluating the benefits of using ICT, financial constraints, and a lack of understanding of the ICT implementation process.

In other research, Ahuja et al. (2009) investigated ICT adoption for building project management in the Indian construction industry. According to their research, 'Non-dependability of IT infrastructure' is not considered as an important barrier for effective adoption of ICT. IT infrastructure at sites was analysed as an important enabler for effective ICT adoption for project management. In addition, their research revealed that the majority of the Small and Medium Enterprises (SMEs) perceived initial cost and cost of updating IT infrastructure to be high 
Table 1. Literature on ICT barriers

\begin{tabular}{|c|c|c|c|c|c|c|c|}
\hline Barriers & & $\begin{array}{c}\text { Love } \\
\text { et al. [24] }\end{array}$ & $\begin{array}{l}\text { Barthorpe } \\
\text { et al. [19] }\end{array}$ & $\begin{array}{l}\text { Frits } \\
{[25]}\end{array}$ & $\begin{array}{c}\text { Gajendran and } \\
\text { Brewer [23] }\end{array}$ & $\begin{array}{l}\text { Ahuja } \\
\text { et al. [20] }\end{array}$ & $\begin{array}{l}\text { Adrianse } \\
\text { et al. [21] }\end{array}$ \\
\hline \multirow[t]{5}{*}{ Cost-related } & Uncertain return on investment & & & & $\cdot$ & & \\
\hline & $\begin{array}{l}\text { Financial constraints / bussiness } \\
\text { requirements }\end{array}$ & • & & • & & & \\
\hline & Investment cost & - & & & & • & \\
\hline & $\begin{array}{l}\text { Unclear benefits of technology } \\
\text { use }\end{array}$ & $\bullet$ & & & & & \\
\hline & $\begin{array}{l}\text { Poor availability of tools for } \\
\text { evaluating the benefits of using } \\
\text { technology }\end{array}$ & & & $\bullet$ & & & \\
\hline \multirow[t]{2}{*}{ Process-related } & $\begin{array}{l}\text { Lack of understanding of the } \\
\text { ICT implementation process }\end{array}$ & & & • & & & \\
\hline & $\begin{array}{l}\text { Traditional practice of } \\
\text { the construction industry } \\
\text { construction industry }\end{array}$ & & $\cdot$ & & & & \\
\hline \multirow{4}{*}{$\begin{array}{l}\text { Technology- } \\
\text { related }\end{array}$} & Lack of an IT infrastructure & $\cdot$ & & & & $\cdot$ & \\
\hline & $\begin{array}{l}\text { Lack of established IT system } \\
\text { standards }\end{array}$ & & $\cdot$ & & & & \\
\hline & $\begin{array}{l}\text { Lack of perceived suitability of } \\
\text { the software }\end{array}$ & & & $\cdot$ & & & \\
\hline & Technology immaturity levels & & & - & & & \\
\hline \multirow[t]{5}{*}{ Other barriers } & $\begin{array}{l}\text { Different working practices, } \\
\text { resources, and the objectives of } \\
\text { the organisations involved }\end{array}$ & & & & & & • \\
\hline & $\begin{array}{l}\text { Fragmented and temporary } \\
\text { nature of construction projects }\end{array}$ & & - & - & & & $\bullet$ \\
\hline & Culture & & & & $\cdot$ & & \\
\hline & Behavioural barriers & $\bullet$ & & & & & \\
\hline & Lack of staff & - & & & & & \\
\hline
\end{tabular}

ranked barrier affecting ICT adoption for building project management.

The identified barriers are divided into four main groups and summarised in Table 1.

\subsection{The significance of the implementation barriers}

The significance of the implementation barriers can be divided into three levels; people (e.g. individuals IT knowledge characteristics), organisation (e.g. resistance to change by staff) and industry (e.g. high cost associated with IT applications) (Stewart et al. 2004; Henderson, Ruikar 2010). Therefore, barriers that influence the success of ICT deployment may come from within any of these levels.

The advancement of information and communication technology cannot be judged by the pace of hardware development alone. Organisational and behavioural problems can affect the effectiveness of the systems (Lam et al. 2010). Thus, the successful use and adoption of new technology needs a carefully managed process. Furthermore, the ICT implementation process should not be looked at in isolation, but must incorporate aspects such as appropriate communication, culture, effective leadership, championship, and environmental or organisational conditions for it to be a success (Anumba et al. 2006).

According to the model developed and investigated by Ahuja et al. (2010a), if strategic ICT adoption is implemented at the industry and organisation levels, this leads to effective information technology adoption by the people within the project teams. In turn, this results in the successful implementation of the strategy at an organisational level, further leading to successful implementation within the industry at a whole. Thus, it is a cyclical process, which in the round would lead to the strategic diffusion of IT for the management of construction projects. As widely understood, there is a direct relationship between people and the organisation within any industry. Also, it is believed that the decision to adopt technology within the construction project is taken at the organisational level (Ahuja et al. 2010a). This research mainly focuses on the research variables at the level of the organisation (organisational constraints) that prevents construction benefiting from the use of ADC technologies.

\subsection{Technology adoption benefits}

The use of ICT applications in construction projects is relatively limited and ineffective when compared to 
other sectors such as the automotive and aerospace industries (Anumba, Ruikar 2002). In order to discuss the opportunities and potential benefits of such systems for the construction industry, several surveys have been conducted in the past couple of years to analyse the use of IT applications and to determine the impact of information technology in the construction industries of various countries (Nitithamyong, Skibniewski 2006; Ahuja et al. 2010a). According to a research, which is conducted on effectiveness of ICT for construction information exchange amongst multidisciplinary project teams, three most important factors for the hindrances between internal and external information exchanges were: (1) need for self-discipline; (2) need for technical support; and (3) systems with inadequate capacity of information transfer (Lam et al. 2010).

Benefits of ICT adoption include continuous access to the information, richer information to aid decision making, greater financial control and communications. Simpler and faster access to common data as well as a decrease in documentation errors are also achieved (Nitithamyong, Skibniewski 2006). With traditional tools of communication, project managers often lose the ability of timely change management (Ahuja et al. 2009). Not only the use of ADC technologies for efficient information management is needed but also the construction industry has greatly benefited from technology in raising the speed of information flow, reducing data entry errors caused by human transcription (Wang et al. 2007). These lead to enhanced efficiency, the effectiveness of information communication, and the reduction of labour costs and cost of information transfer.

Ahuja et al. (2010b) conducted a research to provide construction organisations with a generic benchmarking framework to assess their extent of information and communication technology adoption for building project management processes. According to their research, an increased and improved use of ICT for general administration works within the organisation leads to an improved IT infrastructure within the organisation, development of electronic databases, and staff that are confident using IT tools.

ICT is needed not only to integrate the communication amongst different departments and sub-units of a construction organisation, but also to deliver rapidity of data into the information system (Majrouhi Sardroud, Limbachiya 2011). This would lead to the minimisation of the time and labour used for retrieving information related to each part of the construction process and reduces the occurrence of ineffective decisions made in the absence of information. In addition, using such systems leads to an increase in the speed of work-flow and effective and faster access to common data as well as the possibility of information sharing.

The application of IT engenders a more standardised communication between various participants in the construction industry and facilitates the transmission of information in digital format. Thus, organisations are required to give more attention on strategically increasing technology usage in managerial tasks.

\section{Research methodology}

According to Neuman (2011), a research study can adopt an exploratory, descriptive, and explanatory approach. This study aims to explore, identify and validate the technological, processes, and other qualitative factors relating to the use and adoption of ADC technologies in construction. In addition, this research discusses how these factors support the effective adoption of ADC technologies for construction projects. This survey used consisted principally of data collection through the online-questionnaire. The targeted respondents for this study were drawn internationally from construction sector, which includes five categories: consulting engineers, contractors, academic researchers, owners, and others.

\subsection{Questionnaire design}

An extensive literature survey has enabled the identification of key factors as barriers for ADC technologies adoption in construction, which underpin a questionnaire. All questions were designed as closed-ended to receive more coefficient data in comparison with other kinds of questions and to ensure consistency of respondent feedback (Bourque et al. 2003).

In terms of content, the questionnaire comprised two sections. These were:

\section{Section One}

The questions in this section required respondents to identify their time of experience in the construction industry and their occupation rather researcher, consultant, contractor, owner, or other.

\section{Section Two}

- Part one: respondents' experiences with any type of ADC technologies

This part required respondents to identify their experiences with any type of ADC technologies in construction rather yes or no.

- Part two: respondents' opinion about the identified factors

Questions in this part focused on investigating and ascertaining perceived key factors, associated with the use and adoption of ADC technologies in construction. This part concerned with 19 questions about respondents' opinion about the identified factors to assess the perceptions of respondents regarding the importance of the key factors in adopting ADC technologies. The questionnaire used a five point Likert-type scale to measure a range of opinions. Respondents were invited to rate each factor which required a ranking $1-5$, where 1 and 5 corresponding to 'unimportant' and 'extremely important' respectively, whereas 3 represented 'moderately 
important'. The key identified factors were categorised in four clusters. These clusters were:

Cost related factors:

- High investment;

- Uncertain return on investment;

- Maintenance cost.

Process related factors:

- Lack of understanding of the ADC implementation process;

- Unsure of how to begin this process;

- Difficult to integrate and combine in existing rocess;

- ADC management problems.

Technology related factors:

- ADC immaturity levels;

- Lack of flexibility and adaptability of ADC technologies;

- Lack of reliability;

- Risk of the technical malfunction;

- Limited technical life cycle;

- Needs for infrastructure or network;

- Lack of perceived suitability of the software.

Other factors:

- Lack of economical assessment and business value analysis of ADC use;

- Poor availability of tools for evaluating benefits of using ADC technologies;

- No market information;

- No innovative culture;

- Lack of successful evidence from case studies.

- Part three: respondents' agreement about the statement

This part required respondents' agreement about the statement 'adopting ADC technologies is a promising solution to overcome construction complexity, and it cannot be denied nor ignored'. In this part, respondents were divided into five groups in their opinion about the statement, which required a ranking $1-5$, where 1 and 5 corresponding to 'strongly disagree' and 'strongly agree' respectively, whereas 3 represented 'neutral'.

\subsection{Validity and reliability of the questionnaire}

Discussions with three experts from academy and industry were used to probe, explore, and validate the researched field in more depth and to support content validity of the questionnaire. The main criteria for selecting these experts were their experiences and the type of organisation they work for: contractor, consultant, and research. Small changes have been made in wording of the question to improve the fluency and clarity of the work.

A pilot survey of six selected professionals comprising consultant, contractor, and researcher was conducted as a pre-test to support reliability of the questionnaire before the main survey was undertaken. This pilot test was conducted to obtain responses that would help to identify ambiguous questions and to ensure clarity. A number of the recommended amendments and observations from the pilot survey were used to refine and revise the questionnaire before distributing to the respondents. The Cronbach's Alpha analysis was also carried out using SPSS (Statistical Package for the Social Sciences) software to assess the reliability of the questionnaire. Cronbach's alpha is the most widely used index of the reliability of a scale (Streiner 2003). One factor has been removed to ensure all factors fell within the 0.6 or greater range in terms of reliability ((Nunnally 1978) cited in (Lam et al. 2010)).

In order to help respondents to familiarise themselves with ADC technologies, examples were given at the outset of the questionnaire. After evaluation of the validity and reliability of the questionnaire, emails with the link to the online survey were sent to selected construction professionals. These emails not only provide a link to the survey, but also play essential roles as a covering letter, to assist respondents in understanding the questions posed, indicating information about the purpose of the survey and giving a short description and some examples of the ADC technologies. A sample of the questionnaire can be viewed at the website: http://kingston. qualtrics.com/SE/?SID=SV_31TYpNsqqJTuLUo.

\section{Results and discussion}

The link of the survey was distributed to 112 construction professionals across the globe. This was drawn from published papers in the research field and also from the construction stakeholders of the Construction Opportunity for Mobile IT (COMIT). Of the responses, 38 were returned completed, representing a response rate of $33.9 \%$ (approx. 34\%). In respect of this percentage figure, there is no standard for an acceptable response rate, published opinions (Idrus, Newman 2002) indicates that a response rate of $30 \%$ is acceptable and good enough in construction studies.

Following an initial small sample, 8 key organisations were invited through email contacts to seek their Board of Director (BoD) members' cooperation on the survey. Positive responses were received from 4 organisations, which added 27 usable responses to the survey results. Information about these organisations is given at the end of this paper as an acknowledgment. Nine of the responses were found to be single responses from a country or incomplete and these were discarded. Finally, a total of 65 valid and usable responses were received from the survey during the period of October 2010 and January 2011. Table 2 represents the proportion of respondents from the six countries. Although the results can in no way be considered to be representative of the industry as a whole, they still present useful information and do provide important indications pertinent to the construction industry. 


\subsection{Analysis of respondents}

Upon receiving the responses, the Cronbach's Alpha test was carried out again to check the reliability of the questionnaire. Reliability statistics indicate that the Cronbach's Alpha for this study was 0.777 , being higher than the threshold level of 0.6 as suggested for exploratory research by Nunnally (Nunnally (1978) cited in Lam et al. (2010)).

Table 2. Distribution of respondents by their region

\begin{tabular}{lc}
\hline Country & Number of respondents \\
\hline United Kingdom & 22 \\
\hline United States & 12 \\
\hline Hong Kong & 9 \\
\hline Germany & 8 \\
\hline Canada & 7 \\
\hline India & 7 \\
\hline
\end{tabular}

Table 3. General Respondent Demographics (G.R.D.) characteristics of the respondents

\begin{tabular}{lccc}
\hline G.R.D. & Groups & Frequency & Percent \\
\hline \multirow{4}{*}{ Occupation } & Researcher & 21 & $32.3 \%$ \\
\cline { 2 - 4 } & Contractor & 20 & $30.8 \%$ \\
\cline { 2 - 4 } & Consultant & 14 & $21.5 \%$ \\
\cline { 2 - 4 } & Owner & 4 & $6.2 \%$ \\
\cline { 2 - 4 } & Other & 6 & $9.2 \%$ \\
\hline \multirow{3}{*}{ Experience } & $<4$ years & 9 & $13.8 \%$ \\
\cline { 2 - 4 } & $4-6$ years & 4 & $6.2 \%$ \\
\cline { 2 - 4 } & $7-10$ years & 9 & $13.8 \%$ \\
\cline { 2 - 4 } & $11-15$ years & 13 & $20 \%$ \\
\cline { 2 - 4 } & $>15$ years & 30 & $46.2 \%$ \\
\hline
\end{tabular}

This indicates that answers based on the five-point Likert scale were reliable and internally consistent.

The General Respondent Demographics (GRD) of the respondents revealed that a vast majority of the respondents $(66.2 \%)$ had more than 10 years of experience in the construction industry as shown in Table 3. This indicates that the respondents were very familiar with construction and so could be relied on to provide useful and valid data for the survey. Regarding the respondents' occupation, amongst the respondents, those working as a researcher accounted for $32.3 \%$, with consultant firms $21.5 \%$, with contractor $30.8 \%$, and from owner $6.2 \%$.

As mentioned earlier, respondents were requested in section two of the questionnaire to state about their experiences with any type of ADC technologies in construction. The survey shows that 46 out of $65(70.8 \%)$ of the total respondents have had experiences with using ADC technologies in the construction industry as shown in Table 4.

Experiences of the experts with the different types of ADC technologies vary from very little experience (used in one or two projects) and frequent use (used in the majority of projects). In other words, although using Barcode technology in a construction project has its own benefits, adopting RFID, GPS, and other ADC technologies all together in the construction projects is the main objective of this research. Therefore, having $70.8 \%$ of respondents which already adopted some of ADC technologies shouldn't be considered as a contradictory. However, these experts could better provide useful and valid data based on their experiences.

\subsection{Data analysis and discussion}

In the main part of the international questionnaire survey, respondents' opinions about the priorities of the 19 key

Table 4. Cross tabulation of the respondent's occupation and their experience with using ADC technologies in construction

\begin{tabular}{|c|c|c|c|c|c|}
\hline & & & \multicolumn{2}{|c|}{$\begin{array}{l}\text { Respondent's experience } \\
\text { with using ADC technologies } \\
\text { in the construction industry? }\end{array}$} & \multirow[t]{2}{*}{ Total } \\
\hline & & & Yes & No & \\
\hline \multirow{10}{*}{$\begin{array}{l}\text { Respondent's } \\
\text { occupation }\end{array}$} & \multirow{2}{*}{ Researcher } & Count & 15 & 6 & 21 \\
\hline & & $\%$ within respondent's field of work & $71.4 \%$ & $28.6 \%$ & $100.0 \%$ \\
\hline & \multirow{2}{*}{ Consultant } & Count & 12 & 2 & 14 \\
\hline & & $\%$ within respondent's field of work & $85.7 \%$ & $14.3 \%$ & $100.0 \%$ \\
\hline & \multirow{2}{*}{ Contractor } & Count & 10 & 10 & 20 \\
\hline & & $\%$ within respondent's field of work & $50.0 \%$ & $50.0 \%$ & $100.0 \%$ \\
\hline & \multirow{2}{*}{ Owner } & Count & 3 & 1 & 4 \\
\hline & & $\%$ within respondent's field of work & $75.0 \%$ & $25.0 \%$ & $100.0 \%$ \\
\hline & \multirow{2}{*}{ Other } & Count & 6 & 0 & 6 \\
\hline & & $\%$ within respondent's field of work & $100.0 \%$ & $.0 \%$ & $100.0 \%$ \\
\hline \multirow{2}{*}{ Total } & & Count & 46 & 19 & 65 \\
\hline & & $\%$ within respondent's field of work & $70.8 \%$ & $29.2 \%$ & $100.0 \%$ \\
\hline
\end{tabular}


Table 5. Respondents' opinions about the priorities of the factors from the contractors', consultants', and researchers' points of view

\begin{tabular}{|c|c|c|}
\hline Contractors' opinions & Consultants' opinions & Researchers' opinions \\
\hline Uncertain return on investment & No innovative culture & Uncertain return on investment \\
\hline Lack of understanding ... & Lack of understanding ... & Lack of economical assessment ... \\
\hline Maintenance cost & Lack of successful evidence ... & Lack of understanding ... \\
\hline ADC immaturity levels & Lack of economical assessment ... & ADC immaturity levels \\
\hline ADC management problems & Uncertain return on investment & No innovative culture \\
\hline Lack of economical assessment ... & Unsure of how to begin this process & Lack of reliability \\
\hline Poor availability of tools ... & Poor availability of tools ... & ADC management problems \\
\hline High investment & Difficult to integrate and combine ... & Unsure of how to begin this process \\
\hline No innovative culture & Needs for infrastructure or network & Difficult to integrate and combine ... \\
\hline Difficult to integrate and combine ... & No market information & Poor availability of tools ... \\
\hline Lack of perceived suitability ... & Lack of perceived suitability ... & High investment \\
\hline Lack of successful evidence ... & ADC management problems & Lack of successful evidence ... \\
\hline Risk of technical malfunction & ADC immaturity levels & Limited technical life cycle \\
\hline Limited technical life cycle & Lack of flexibility and adaptability ... & Risk of technical malfunction \\
\hline Needs for infrastructure & High investment & No market information \\
\hline No market information & Lack of reliability & Maintenance cost \\
\hline Lack of reliability & Maintenance cost & Lack of perceived suitability ... \\
\hline Lack of flexibility and adaptability ... & Limited technical life cycle & Needs for infrastructure or network \\
\hline Unsure of how to begin this process & Risk of technical malfunction & Lack of flexibility and adaptability . \\
\hline
\end{tabular}

identified factors were obtained. In addition, they were asked about their thoughts on this statement: 'adopting ADC technologies is a promising solution to overcome construction complexity, and it cannot be denied nor ignored'. The main findings of the survey are alnalysed and discussed in this section.

Remarkable as it is, the importance level of all 19 perceived factors were of moderate importance or higher than this level of importance. The results further indicated that, importance level of the process related factors are higher than technology related factors. The survey also showed that $36.9 \%$ of the respondents believe that 'uncertain return on investment' is extremely important, and also $44.6 \%$ of them expressed as their opinion that it is very important. Thus, this factor has found highest importance level amongst all perceived factors. Table 5 represents the respondents' opinions about the priorities of the factors in descending order from the contractors', consultants', and researchers' points of view.

According to the Table 5, 'Uncertain return on investment' which is one of the cluster of cost related factors, has found the highest importance level amongst all factors from contractors' and researchers' points of view, Whereas from consultants' point of view, 'No innovative culture' received the highest level of importance.

Figure 1 represents the importance level of the clusters from contractors', consultants' and researchers' points of view. According to Figure 1, the cluster of technology related factors received the lowest level of importance amongst all clusters. Thus, the barriers of ADC technology use and adoption have moved beyond technical problems, as stated earlier in the literature review. However, cost related problems still remain as barrier from contractors' and researchers' points of view.

Table 6 represents the cross tabulation of the findings from the survey for respondents' agreement about the statement, together with their experience with using ADC technologies within the construction industry. There was a $78.5 \%$ (51 out of 65 ) consensus amongst the respondents that construction cannot continue without adopting the ADC technologies. These respondents stated that they agreed or strongly agreed with adopting ADC technologies to overcome construction complexity. Significantly, results show that $84.8 \%$ (39 out of 46 )

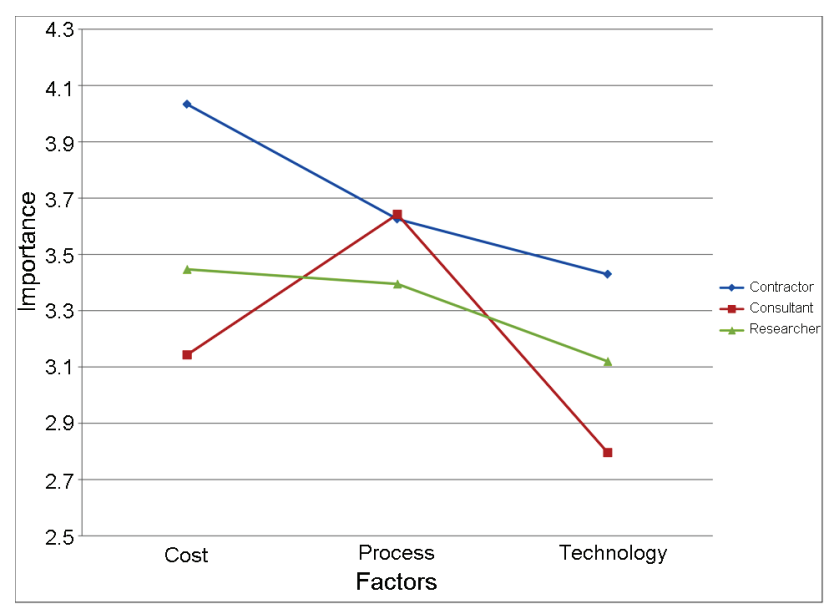

Fig. 1. Importance level of the clusters from the contractors', consultants', and researchers' points of view 
Table 6. Cross tabulation of the respondent's agreement about the statement, their experience with using ADC technologies in construction, together with their occupation

\begin{tabular}{|c|c|c|c|c|c|c|c|c|c|}
\hline \multicolumn{4}{|c|}{$\begin{array}{l}\text { Do you have any experience with using ADC } \\
\text { technologies in the construction industry? }\end{array}$} & \multicolumn{5}{|c|}{ Respondent's occupation } & \multirow[t]{2}{*}{ Total } \\
\hline \multirow[t]{11}{*}{ Yes } & \multirow{9}{*}{$\begin{array}{l}\text { Statement: } \\
\text { "Adopting ADC } \\
\text { technologies is a } \\
\text { promising solution } \\
\text { to overcome } \\
\text { construction } \\
\text { complexity and it } \\
\text { cannot be denied } \\
\text { nor ignored." }\end{array}$} & & & Researcher & Consultant & Contractor & Owner & Other & \\
\hline & & \multirow{2}{*}{$\begin{array}{l}\text { Strongly } \\
\text { disagree }\end{array}$} & Count & 1 & 0 & 0 & 0 & 0 & 1 \\
\hline & & & $\begin{array}{l}\text { \% within } \\
\text { respondent's } \\
\text { field of work }\end{array}$ & $6.7 \%$ & $.0 \%$ & $.0 \%$ & $.0 \%$ & $.0 \%$ & $2.2 \%$ \\
\hline & & \multirow[t]{2}{*}{ Neutral } & Count & 3 & 2 & 0 & 1 & 0 & 6 \\
\hline & & & $\begin{array}{l}\text { \% within } \\
\text { respondent's } \\
\text { field of work }\end{array}$ & $20.0 \%$ & $16.7 \%$ & $.0 \%$ & $33.3 \%$ & $.0 \%$ & $13.0 \%$ \\
\hline & & \multirow[t]{2}{*}{ Agree } & Count & 5 & 4 & 6 & 2 & 5 & 22 \\
\hline & & & $\begin{array}{l}\text { \% within } \\
\text { respondent's } \\
\text { field of work }\end{array}$ & $33.3 \%$ & $33.3 \%$ & $60.0 \%$ & $66.7 \%$ & $83.3 \%$ & $47.8 \%$ \\
\hline & & \multirow{2}{*}{$\begin{array}{l}\text { Strongly } \\
\text { agree }\end{array}$} & Count & 6 & 6 & 4 & 0 & 1 & 17 \\
\hline & & & $\begin{array}{l}\text { \% within } \\
\text { respondent's } \\
\text { field of work }\end{array}$ & $40.0 \%$ & $50.0 \%$ & $40.0 \%$ & $.0 \%$ & $16.7 \%$ & $37.0 \%$ \\
\hline & \multirow[t]{2}{*}{ Total } & & Count & 15 & 12 & 10 & 3 & 6 & 46 \\
\hline & & & $\begin{array}{l}\text { \% within } \\
\text { respondent's } \\
\text { field of work }\end{array}$ & $100.0 \%$ & $100.0 \%$ & $100.0 \%$ & $100.0 \%$ & $100.0 \%$ & $100.0 \%$ \\
\hline \multirow[t]{8}{*}{ No } & \multirow{6}{*}{$\begin{array}{l}\text { Statement: } \\
\text { "Adopting ADC } \\
\text { technologies is a } \\
\text { promising solution } \\
\text { to overcome } \\
\text { construction } \\
\text { complexity and it } \\
\text { cannot be denied } \\
\text { nor ignored." }\end{array}$} & \multirow[t]{2}{*}{ Neutral } & Count & 1 & 0 & 6 & 0 & 0 & 7 \\
\hline & & & $\begin{array}{l}\text { \% within } \\
\text { respondent's } \\
\text { field of work }\end{array}$ & $16.7 \%$ & $.0 \%$ & $60.0 \%$ & $.0 \%$ & $.0 \%$ & $36.8 \%$ \\
\hline & & \multirow[t]{2}{*}{ Agree } & Count & 3 & 0 & 2 & 0 & 0 & 5 \\
\hline & & & $\begin{array}{l}\text { \% within } \\
\text { respondent's } \\
\text { field of work }\end{array}$ & $50.0 \%$ & $.0 \%$ & $20.0 \%$ & $.0 \%$ & $.0 \%$ & $26.3 \%$ \\
\hline & & \multirow{2}{*}{$\begin{array}{l}\text { Strongly } \\
\text { agree }\end{array}$} & Count & 2 & 2 & 2 & 1 & 0 & 7 \\
\hline & & & $\begin{array}{l}\% \text { within } \\
\text { respondent's } \\
\text { field of work }\end{array}$ & $33.3 \%$ & $100.0 \%$ & $20.0 \%$ & $100.0 \%$ & $.0 \%$ & $36.8 \%$ \\
\hline & \multirow[t]{2}{*}{ Total } & & Count & 6 & 2 & 10 & 1 & 0 & 19 \\
\hline & & & $\begin{array}{l}\text { \% within } \\
\text { respondent's } \\
\text { field of work }\end{array}$ & $100.0 \%$ & $100.0 \%$ & $100.0 \%$ & $100.0 \%$ & $.0 \%$ & $100.0 \%$ \\
\hline
\end{tabular}

of the respondents, which have had experience with using ADC technologies in construction agreed or strongly agreed with the statement. The results also do reveal that, $81.4 \%$ (35 out of 43 ) of the respondents, whom had more than 10 years experience, also agreed or strongly agreed with the statement. The following sub-sections detail categorised factors within the four clusters, and provide some solutions to overcome the investigated barriers.

\subsubsection{Cost-related factors}

As stated earlier, 'uncertain return on investment' is seen to have the highest importance level amongst all perceived factors. In order to decrease uncertainty of return on investment, appropriate tools and methods should be developed by researchers to evaluate benefits of using
ADC technologies, and to clarify rate of return.

Another cost-related factor, 'Maintenance cost' rated highly as a barrier by contractors, whilst from the consultants' and researchers' points of view this factor received a low level of importance. This necessitates the creation of guidelines for any applications in terms of maintenance and technology management itself. This will help practitioners to have special care and continuous monitoring, step-by-step throughout the operational stage in the process.

In summing up, the construction industry suffers from low investment in technology, and cost-related factors play an essential role in the adoption of ADC technologies in this industry. One possible reason is due to the nature of the industry, which is conservative in the 
uptake of new technologies where the main incentive has been cost saving in execution of projects. Another reason is due to lack of clear strategy and actual implementation processes, which can lead to moderate technological investment costs. Although some of the identified issues require strategic initiatives from the construction companies, and ADC technology investments should be increased, the cost of ICT infrastructure should be made more affordable.

\subsubsection{Process-related factors}

The 'Lack of understanding of the ADC implementation process' is rated by three main groups of respondents (contractors, consultants, and researchers) at the same level of importance. Because of this, creation of a flowchart for any application is necessary. This will help contractors decide the right technology and application, most appropriate for their needs. As it is known, a flow chart is an easy-to-understand graphical or diagrammatic representation of a process. The flow chart can give the process flow at a glance, which helps to define and analyse process step-by-step. It helps visualise how a particular job is done and thereby can be used to find areas that need to be improved and solution to a given problem.

In some cases, the comparison between construction and other industries may help the practitioners in deciding the right concept. Having this kind of flowchart not only will make integration and combination of such system in existing process possible, but also leads to understanding of process inception by practitioners. Table 9 represents the respondents' opinions concerning the 'lack of understanding of the ADC implementation process' as a barrier, together with their occupation.

The majority of the construction organisations suffer from the lack of ICT staff in implementing any technology in their projects. This may result in 'ADC management problems', which is highlighted by contractors. Although consultant organisations can play essential roles in conducting the management strategies to overcome this barrier, ICT resources of the companies need to be increased. It cannot be denied nor ignored. Furthermore, for a successful and effective adoption of new technologies, special care and continuous management attention, throughout the actual implementation stage, has to be given to the step-by-step process.

Wide Implementation of the technology would bring resistance from companies as they have been using traditional and comfortable methods. Thus, one of the expected challenges in adopting the technology, which can affect successful innovation, is social challenges. Harty suggested that social aspects need to be taken in account to understand the adoption of technology (Harty(2005) cited in Adriaanse et al. (2010b)). Consequently, not only extra efforts and training are needed, but also it is important to provide strong incentives for enterprises for adoption of new technologies.

\subsubsection{Technology-related factors}

Amongst technology-related factors, 'ADC immaturity levels' rated highly as a barrier, and above the other factors in this cluster. This factor has received the same position from the contractor's point of view. Maturity indicates the degree of advancement of technology utilisation (Idrus, Newman 2002). It is of great importance for practical implementation, which necessitates analysis of phases in ADC technologies advancement.

\subsubsection{Other factors}

Availability of appropriate tools and mechanisms for evaluating the benefits of using ADC technologies, not only supports the economical assessment and business value analysis, but also leads to demonstrate their costeffectiveness and practical application benefits. In other words, conducting a cost-benefit analysis persuades this industry to try such a system where they are unwilling to invest in new and costly technology.

Technology manufacturers must take the lead in the standardisation effort. Furthermore, they must present best practices and successful evidence from case studies to the construction industry to get full investment. These case studies should be done in real construction projects in terms of scale and conditions.

\section{Framework for ADC technology usage in the construction industry}

The above presented data analysis lead to the identification of issues, which require action at the levels of industry and organisation. There is a need for a strategic plan, which will give further explanation about the responsibilities of the industry and construction companies. This strategic plan should address all related issues to support the wider use of ADC technologies in the construction industry. In order to achieve success with the ADC systems: firstly, a management team must be created at early phase of the project. This team may be from the owner side, from the main contractor, or both of them. The team has to be responsible for purchasing and implementing the system. Secondly, necessary training is required for construction workers and managers to ensure successful implementing and running the system.

There is also a need for a framework that attempts to bridge the gap between academic institutions and industry. This framework should be suitable for the systematic investigation of the automated data acquisition technologies in the architectural, engineering, construction, and operational industries. The framework clarifies the implementation requirements, and addresses all key issues in the ADC technology field in an efficient way. This will lead to facilitate the strategic adoption and deployment of $\mathrm{ADC}$ technologies in the construction industry.

Although some applications of ADC technology in the construction industry already exist, there have been 


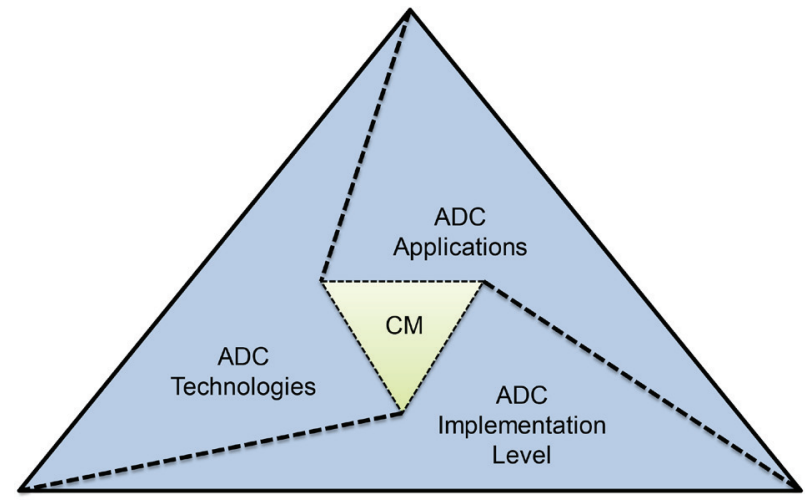

Fig. 2. Construction management and ADC technologies

limited efforts in systematically defining their concepts as a framework for implementation. Available frameworks and reports from other industries and other related domains in the construction industry such as Building Information Modelling (BIM) (Jung, Joo 2011; Succar 2009), virtual design and construction (Fischer, Kunz 2005), building product models (Eastman 1999), and asset lifecycle information system (FIATECH 2007) may help the industry for a successful implementation of ADC technologies in real world scenarios. Figure 2 shows three main parts of the possible framework which will support ADC technology usage in Construction Management (CM).

ADC implementation requirements are represented in the framework which is shown in Figure 3. The framework comprises three main parts:
- ADC technology implementation level;

- ADC technology utilisation and standards;

- ADC applications in the construction industry.

\subsection{ADC technology implementation level}

Three levels of implementation in this framework include the project and people level, the organisation level, and the industry level. Due to the fact that different levels of implementation requires different criteria for utilisation and standardisation of products and processes, these levels of implementation need to be considered at the same time for specific ADC technology implementation. This not only improves inter-organisational communication and coordination, but also enhances information sharing and intraorganisational collaboration amongst the project participants. This leads to an approach with an integrated practice.

\subsection{ADC technology utilisation and standards}

Amongst the three main parts of the framework, 'ADC technology' is further divided into two important categories; standardisation, and utilisation. Although technology standards may be available from an industry perspective, issues of the ADC standards and practical details should be addressed for the three levels of implementation. These details support an approach of integrated practices amongst the involved participants of any project by the modelling and exchanging of any products and processes within the construction industry.

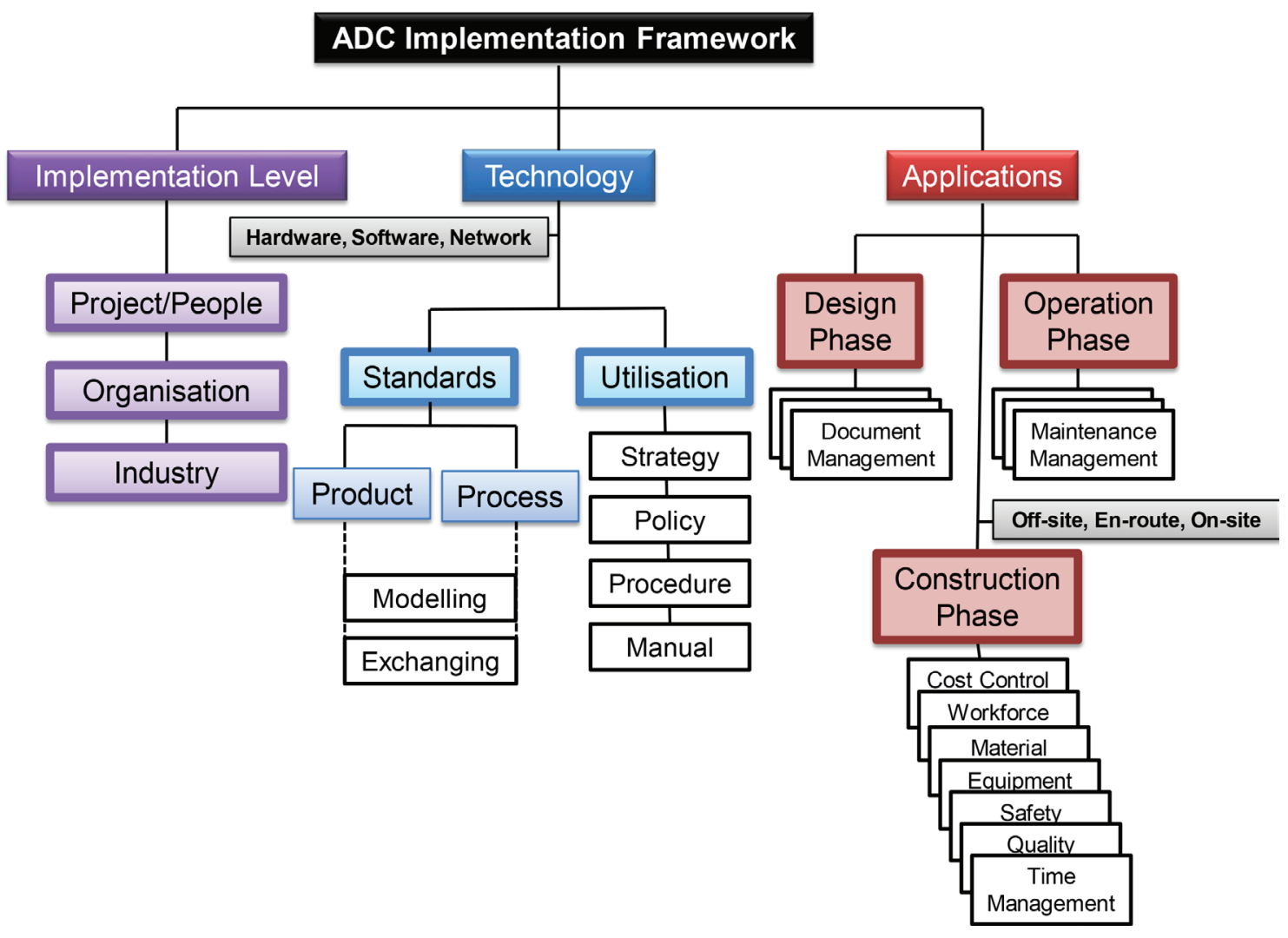

Fig. 3. Implementation framework for ADC technology in the construction industry 
According to Jung and Joo (2011) the utilisation variables consist of strategy, policy, procedures, and manuals, which are vital for successful implementation. Strategy and policy direct all activities within an organisation, and consequently characterise distinct requirements of information systems [Ibid.]. Therefore, for practical implication and successful implementation of ADC technologies in this industry, implementation strategies and policies should be examined and evaluated.

Industry needs to focus on creating a learning atmosphere through education programs and training facilities, which will lead to an improvement in ADC technology adoption at an industry level. This will increase the ICT capabilities of construction companies. In addition, at the industry level in any country, national bodies should create awareness about the ADC technologies and their implementation processes. This will lead to an increase in the level of practical knowledge for all concerned, generating an interface between industry and academics through conferences and seminars.

Designing $\mathrm{ADC}$ interfaces require procedures as tools for systemisation or standardisation of ADC applications in the construction industry. This always leads to obtaining the same results under the same circumstances. Finally, well organised manuals can facilitate automated operations by reflecting distinct characteristics of a project or an organisation (Jung, Kang 2007).

\subsection{ADC applications in the construction industry}

Applications of automated data acquisition technologies, in the construction industry, should cover three major lifecycle phases of the projects including the design, construction, and operation phases. Each phase has its own characteristics and environment, and hence classification may differ depending on their different needs. Good examples of design and operation phases are document and maintenance management. However, there are important functions for these technologies in the construction phase. This framework highlights some of these management functions, including workforce, materials, equipment, safety, quality, cost, and time. The identified applications in the construction phase should support three stages of the production site (off-site), shipping (en-route), and job site (on-site) in any construction project.

On the other hand, the majority of possible applications explored by researchers mostly relate to certain segments of the entire process with their own characteristics and environment. Therefore, specific research results cannot be generalised for other processes. Thus, in summation, there are many promising functions for ADC technologies in the construction industry, which can be clarified and systemised by the proposed framework.

\section{Conclusions}

Literature related to the use and adoption of ICT and ADC technologies in the construction industry is comprehensively reviewed in this paper. In total, 19 key factors are identified and validated as barriers through an online questionnaire survey. These factors are grouped into those which are cost related, technology related, process related, and other factors. This research reports the findings of the questionnaire survey conducted amongst the 65 professionals of the construction industry around the world, aimed at collecting their perceptions regarding $\mathrm{ADC}$ technology adoption barriers in the construction industry. The results show that the importance level of all 19 identified factors were of moderate importance or higher than this level of importance. The results also indicated that the importance level of all process related factors are higher than technology related factors. According to the results, the first four rankings in descending order are: 1) Uncertain return on investment; 2) Lack of understanding of the ADC implementation process; 3) Lack of economical assessment and business value analysis of ADC use; and 4) No innovative culture. There was a $78.5 \%$ consensus amongst the respondents that construction cannot continue without the adoption of ADC technologies. This shows that there is a need for research on ADC technology adoption strategies, together with actual ADC implementation within the construction industry. This paper also introduces an implementation framework for ADC technology in the construction industry. The proposed framework provides some useful insights into ADC technology adoption within the construction industry. This could form the backbone of technology adoption in real scenarios by identifying driving factors. It is hoped that the findings of this research will help future researchers seeking solutions in the challenges relating to the adoption and implementation of the ADC technologies.

\section{Research limitation}

Although we maintain that our research provides strategic results about $\mathrm{ADC}$ technologies adoption in construction, a larger sample may produce a better result. In addition, ADC technologies are a relatively new technology and therefore, some respondents were unfamiliar with the ADC applications, which is a limitation of this research. However, as far as we know, this is a pioneering study, which looks at perceptions of the ADC technologies usage in the construction industry, and provides useful information for future research in terms of strategies, to promote automated data collection technologies in the construction industry.

\section{Acknowledgments}

We would like to thank all the respondents who took the time to answer the questionnaire. This survey would not have been possible without the help of: The International 
Association for Automation and Robotics in Construction (IAARC), The International Council for Research and Innovation in Building and Construction (CIB), European Group for Intelligent Computing in Engineering (EG-ICE), The RFID in Construction Consortium, and Construction Opportunities for Mobile IT (COMIT).

\section{References}

Adriaanse, A.; Voordijk, H.; Dewulf, G. 2010a. Adoption and use of interorganizational ICT in a construction project, Journal of Construction Engineering and Management 136(9): 1003-1014. http://dx.doi.org/10.1061/(ASCE)CO.1943-7862.0000201

Adriaanse, A.; Voordijk, H.; Dewulf, G. 2010b. The use of interorganisational ICT in United States construction projects, Automation in Construction 19(1): 73-83. http://dx.doi.org/10.1016/j.autcon.2009.09.004

Ahuja, V.; Yang, J.; Shankar, R. 2010a. IT-enhanced communication protocols for building project management, Engineering, Construction and Architectural Management 17(2): 159-179. http://dx.doi.org/10.1108/09699981011024678

Ahuja, V.; Yang, J.; Shankar, R. 2010b. Benchmarking framework to measure extent of ICT adoption for building project management, Journal of Construction Engineering and Management 136(5): 538-545. http://dx.doi.org/10.1061/(ASCE)CO.1943-7862.0000155

Ahuja, V.; Yang, J.; Shankar, R. 2009. Study of ICT adoption for building project management in the Indian construction industry, Automation in Construction 18(4): 415-423. http://dx.doi.org/10.1016/j.autcon.2008.10.009

Anumba, C. J.; Ruikar, K. 2002. Electronic commerce in construction trends and prospects, Automation in Construction 11(3): 265-275. http://dx.doi.org/10.1016/S0926-5805(01)00087-5

Anumba, E. H. C.; Dainty, A.; Ison, S.; Sergeant, A. 2006. Understanding structural and cultural impediments to ICT system integration: a GIS-based case study, Engineering, Construction and Architectural Management 13(6): 616-633. http://dx.doi.org/10.1108/09699980610712409

Barthorpe, S.; Chien, H. J.; Shih, J. K. C. 2003. The current state of ICT usage by UK construction companies, International Journal of Electronic Business 1(4): 358-371. http://dx.doi.org/10.1504/IJEB.2003.004109

Behzadan, A. H.; Aziz, Z.; Anumba, C. J.; Kamat, V. R. 2008. Ubiquitous location tracking for context-specific information delivery on construction sites, Automation in Construction 17(6): 737-748. http://dx.doi.org/10.1016/j.autcon.2008.02.002

Bourque, L. B.; Fink, A.; Fielder, E. P. 2003. How to conduct self-administered and mail surveys. Thousand Oaks, California, US: Sag Publications Inc.

Bowden, S.; Dorr, A.; Thorpe, T.; Anumba, C. 2006. Mobile ICT support for construction process improvement, Automation in Construction 15(5): 664-676. http://dx.doi.org/10.1016/j.autcon.2005.08.004

Caldas, C. H.; Torrent, D. G.; Haas, C. T. 2004. Integration of automated data collection technologies for real-time field materials management, in Proc. of $21^{\text {st }}$ International Symposium on Automation and Robotics in Construction (ISARC 2004), 21-25 September, 2004, Jeju, Korea, 2004.

Eastman, C. 1999. Building product models: computer environments supporting design and construction. Florida, USA: CRC Press. 424 p.

FIATECH, 2007. Capital Projects Technology Roadmap [online], [cited 13 March 2010]. USA: FIATECH. Available from Internet:

http://www.fiatech.org/projects/roadmap/cptri.htm
Fischer, M.; Kunz, J. 2005. Virtual design and construction: themes, case studies and implementation suggestions. California, USA: Centre for Integrated Facility Engineering, Stanford University. $50 \mathrm{p}$.

Frits, S. 2007. Strategy to enhance use of ICT in construction, in Proc. of CIB World Building Congress 'Construction for Development', 14-18 May, 2007, Cape Town, South Africa, 2007.

Gajendran, T.; Brewer, G. 2007. Integration of information and communication technology: Influence of the cultural environment, Engineering, Construction and Architectural Management 14(6): 532-549.

http://dx.doi.org/10.1108/09699980710829003

Harty, C. 2005. Innovation in construction: a sociology of technology approach, Building Research \& Information 33(6): 512-522. http://dx.doi.org/10.1080/09613210500288605

Henderson, J. R.; Ruikar, K. 2010. Technology implementation strategies for construction organisations, Engineering, Construction and Architectural Management 17(3): 309-327. http://dx.doi.org/10.1108/09699981011038097

Idrus, A. B.; Newman, J. B. 2002. Construction related factors influencing choice of concrete floor systems, Construction Management and Economics 20(2002): 13-19. http://dx.doi.org/10.1080/01446190110101218

Jung, Y.; Joo, M. 2011. Building information modelling (BIM) framework for practical implementation, Automation in Construction 20(2): 126-133. http://dx.doi.org/10.1016/j.autcon.2010.09.010

Jung, Y.; Kang, S. 2007. Knowledge-based standard progress measurement for integrated cost and schedule performance control, Journal of Construction Engineering and Management ASCE 133(1): 10-21.

Lam, P. T. I.; Wong, F. W. H.; Tse, K. T. C. 2010. Effectiveness of ICT for construction information exchange among multidisciplinary project teams, Journal of Computing in Civil Engineering 24(4): 365-376.

http://dx.doi.org/10.1061/(ASCE)CP.1943-5487.0000038

Liang, X.; Lu, M.; Zhang, J. P. 2011. On-site visualization of building component erection enabled by integration of four-dimensional modeling and automated surveying, $\mathrm{Au}$ tomation in Construction 20(3): 236-246. http://dx.doi.org/10.1016/j.autcon.2010.10.002

Love, P. E. D.; Irani, Z.; Edwards, D. J. 2004. Industry-centric benchmarking of information technology benefits, costs and risks for small-to-medium sized enterprises in construction, Automation in Construction 13(4): 507-524. http://dx.doi.org/10.1016/j.autcon.2004.02.002

Love, P. E. D.; Irani, Z.; Li, H.; Cheng, E. W. L.; Tse, R. Y. C. 2001. An empirical analysis of the barriers to implementing e-commerce in small-medium sized construction contractors in the state of Victoria, Australia, Construction Innovation: Information, Process, Management 1(1): 31-41.

Majrouhi Sardroud, J. 2012. Influence of RFID technology on automated management of construction materials and components, Scientia Iranica A 19(3): 381-392. http://dx.doi.org/10.1016/j.scient.2012.02.023

Majrouhi Sardroud, J.; Limbachiya, M. C. 2011. Towards linking islands of information within construction projects utilizing RF technologies, in Gelman, L.; Ao, S. I. (Eds.). Electrical Engineering and Applied Computing. Springer, 197-208.

Majrouhi Sardroud, J.; Limbachiya, M. C. 2010. Effective information delivery at construction phase with integrated application of RFID, GPS and GSM technology, Lecture Notes in Engineering and Computer Science 2183(1): 425-431.

Navon, R. 2007. Research in automated measurement of project performance indicators, Automation in Construction 6(2): 176-188. http://dx.doi.org/10.1016/j.autcon.2006.03.003 
Navon, R. 2005. Automated project performance control of construction projects, Automation in Construction 14(4): 467-476. http://dx.doi.org/10.1016/j.autcon.2004.09.006

Navon, R.; Goldschmidt, E. 2002. Monitoring labor inputs: automated-data-collection model and enabling technologies, Automation in Construction 12(2): 185-199. http://dx.doi.org/10.1016/S0926-5805(02)00043-2

Navon, R.; Goldschmidt, E.; Shpatnisky, Y. 2004. A concept proving prototype of automated earthmoving control, Automation in Construction 13(2): 225-239. http://dx.doi.org/10.1016/j.autcon.2003.08.002

Navon, R.; Sacks, R. 2007. Assessing research issues in Automated Project Performance Control (APPC), Automation in Construction 16(4): 474-484. http://dx.doi.org/10.1016/j.autcon.2006.08.001

Neuman, W. L. 2011. Social Research Methods: Qualitative and Quantitative Approaches. United States: Pearson. 631 p.

Nigithamyong, P.; Skibniewski, M. J. 2004. Web-based construction project management systems: how to make them successful?, Automation in Construction 13(4): 491-506. http://dx.doi.org/10.1016/j.autcon.2004.02.003

Nitithamyong, P.; Skibniewski, M. J. 2006. Success/failure factors and performance measures of web-based construction project management systems: professionals' viewpoint, Journal of Construction Engineering and Management 132(1): 80-87.

http://dx.doi.org/10.1061/(ASCE)0733-9364(2006)132:1(80)

Nunnally, J. C. 1978. Psychometric theory. New York, USA: McGraw-Hill. 701 p.

O'Brien, W. J. 2000. Implementation issues in project web sites: a practioner's viewpoint, Journal of Management in Engineering 16(3): 34-39.

http://dx.doi.org/10.1061/(ASCE)0742-597X(2000)16:3(34)

Peansupap, V.; Walker, D. 2005. Factors affecting ICT diffusion: a case study of three large Australian construction contractors, Engineering, Construction and Architectural Management 12(1): 21-37.

http://dx.doi.org/10.1108/09699980510576871
Razavi, S. N.; Haas, C. T. 2010. Multisensor data fusion for on-site materials tracking in construction, Automation in Construction 19(8): 1037-1046. http://dx.doi.org/10.1016/j.autcon.2010.07.017

Song, J.; Haas, C. T.; Caldas, C. H. 2007. A proximity-based method for locating RFID tagged objects, Advanced Engineering Informatics 21(4): 367-376.

http://dx.doi.org/10.1016/j.aei.2006.09.002

Song, J.; Haas, C. T.; Caldas, C. H.; Ergen, E.; Akinci, B. 2006. Automating the task of tracking the delivery and receipt of fabricated pipe spools in industrial projects, Automation in Construction 15(2): 166-177. http://dx.doi.org/10.1016/j.autcon.2005.03.001

Stewart, R. A.; Mohamed, S.; Marosszeky, M. 2004. An empirical investigation into the link between information technology implementation barriers and coping strategies in the Australian construction industry, Construction Innovation: Information, Process, Management 4(3): $155-171$.

Streiner, D. L. 2003. Starting at the beginning: an introduction to coefficient alpha and internal consistency, J. of Personality Assessment 80(1): 99-103. http://dx.doi.org/10.1207/S15327752JPA8001_18

Succar, B. 2009. Building information modelling framework: a research and delivery foundation for industry stakeholders, Automation in Construction 18(3): 357-375. http://dx.doi.org/10.1016/j.autcon.2008.10.003

Wang, L. C.; Lin, Y. C.; Lin, P. H. 2007. Dynamic mobile RFID-based supply chain control and management system in construction, Advanced Engineering Informatics 21(4): 377-390. http://dx.doi.org/10.1016/j.aei.2006.09.003

Zavadskas, E. K. 2010. Automation and robotics in construction: International research and achievements, Automation in Construction 19(3): 286-290.

http://dx.doi.org/10.1016/j.autcon.2009.12.011

Javad MAJROUHI SARDROUD. He holds an MS degree in Structural Engineering from Tabriz University, Iran, and has a PhD degree in Construction Management. He has a broad background in Civil-Water Engineering, and specialises in structural elements of a built environment. He also has 15 years of practical experience in Construction Management, including contracting, consulting, and ownership. He has been most fortunate in his $\mathrm{PhD}$ research to have had ample opportunity to investigate the role of automated data collection technologies in enhancing the task of monitoring and automated managing of the construction, towards smart materials and construction. He is currently a Senior Academic Member and Lecturer in the Faculty of Engineering at Azad University, Central Tehran Branch, Iran. In the light of above experience and beyond his research successes (including publications to date and others in preparation), he has a very vast vision on the real scenario of building/construction industry and other aspects of an infrastructure that creates a built environment. His research interests include the role of automated data collection technologies in enhancing the monitoring and automated managing of construction, smart materials and construction. 